apparatus for higher power micrography and using a $16 \mathrm{~mm}$. Cine-Kodak Special camera to record the images. Owing to the employment of living specimens, a rotating sector shutter was used to prevent overheating and the whole of the microscope stage was enclosed in an incubator, the necessary controls being outside. The heating elements were two 30 -watt carbon filament lamps shielded to prevent direct rays reaching the object and a chloroform-mercury thermostat next to it. As in the first apparatus, the light was provided by a 100 c.p. Pointolite lamp. Mr. Weston showed a film of the movement of the leucocytes among the red corpuscles of the blood, and higher magnifications showed very clearly the triple nuclei.

\section{Electrical Accidents}

Is a memorandum (J. Inst. Elec. Eng., 91, Pt. I, No. 43 ; July 1944) which assesses electrical accidents in relation to other accidents, and includes an appraisement of some electrical fire statistics, the published statistics of fatal accidents in Great Britain are analysed and the proportion of those of electrical origin are assessed in their relationship to the whole with special consideration of those occurring on domestic premises. Certain statistics concerning fires attributed to electrical causes in both domestic and industrial premises are studied, and the contributing factors are analysed in the order of their importance. It is concluded that electrical accidents have shown no significant increase in relation to the increased use of electricity. The number of fatal accidents due to defective installations tends towards a very low figure; but increasing attention should be given to the quality and maintenance of flexible connexions of the portable appliances employed in domestic situations and to the design and maintenance of the appliances themselves.

Statistics on the incidence of electrically caused fires are not adequate and do not give precise information on the primary causes of such fires. It appears that some 35 per cent of all fires attributed to electrical causes arise from faults in the fixed installations; but of the total fires attended, only $1 \cdot 7-3 \cdot 5$ per cent are attributable to installation defects. The figure for domestic and similar premises is deemed to be lower than this, while the effect of improved techniques, the elimination of D.c. supplies, the use of new materials, and the provision of installations integrally planned in relation to other services in the structure, will all tend to produce a further reduction in the risks. A study of the commoner causes of fires indicates that, in addition to an expected decline in electrically caused fires in proportion to the utilization of electricity, a substantial decrease in the total number of fires is likely to occur as electricity supplants other fuels as a means for space-heating, water-heating and cooking.

\section{Royal Society of Edinburgh : New Officers}

AT the annual meeting of the Royal Society of Edinburgh held on October 23, the following officers were elected : President, Sir William Wright Smith; Vice-Presidents, Prof. T. H. Milroy, Sir John Boyd Orr, Dr. A. W. Greenwood, Prof. E. Hindle, Dr. D. Russell, Prof. R. J. D. Graham; General Secretary, Prof. J. P. Kendall ; Secretaries to Ordinary Meetings, Prof. W. M. H. Greaves, Prof. A. Holmes ; Treasurer, Sir E. M. Wedderburn; Curator of Library and Museum, Dr. J. E. Mackenzie; Councillors, Mr.
Stanley Cursiter, Dr. Douglas Guthrie, Prof. J. W. Heslop Harrison, Mr. A. W. Young, Prof. E. T. Copson, Lieut.-Colonel W. F. Harvey, Prof. A. E. Trueman, Prof. J. Walton, Prof. T. Alty, Mr. J. Morrison Caie, Sir Robert Muir, Sir David K. Murray.

\section{Announcements}

The Joint Committee of the Royal Physical Society, the Royal Scottish Geographical Society and the Royal Society of Edinburgh has awarded the Dr. W. S. Bruce Memorial Prize (1944) to Lieut. T. H. Manning, R.C.N.V.R., for his valuable survey and biological work during 1931-39 in Iceland, Lapland, Southampton Island; Hudson Bay and at Foxe Basin (1936-39).

After the liberation of Paris, the secretary of the British Association was enabled, through the courtesy of M. Louis Rapkine, of the Mission scientifique française en Grande-Bretagne, to address a letter of goodwill to Prof. A. Verne, secretary-general of the French Association for the Advancement of Science. A message of greeting and hope for the early renewal of active relations between the two Associations has now been received by the Council of the British Association from Prof. Verne on behalf of the president and bureau of the French Association.

Dr. A. N. MAY, lecturer in physics at King's College, University of London, has been appointed as from October 1 to the University readership in physics tenable at King's College. Since 1942 Dr. May has been on war service with the Department of Scientific and Industrial Research.

The following doctorates have been conferred by the University of London: D.Sc. on C. N. Acharya, Rothamsted Experimental Station; A. L. Green, King's College ; Miss L. E. Hawker, Imperial College of Science and Technology. D.Sc.(Econ.) on B. R. Misra, London School of Economies.

THE following appointments have recently been made by the Colonial Office: R. J. Dewar and J. G. McQuillen, to be assistant conservators of forests, Nigeria; K. W. Aspinall, to be veterinary officer, Tanganyika; J. J. Steyn, to be entomologist, Uganda ; J. N. Clothier and R. H. Fraser, agricultural officers, Northern Rhodesia, to be senior agricultural officers, Northern Rhodesia; D. F. Macpherson, veterinary officer, Kenya, to be senior veterinary officer, Kenya.

AN exhibition of historic scientific instruments and books, drawn from the collection which Mr. R. S. Whipple is presenting to the University of Cambridge, will be held in the. East Room of the Old Schools during November 4-11. The exhibition will be opened by Sir Henry Dale, president of the Royal Society, on November 4 at 2.45 p.m., and will remain open on weekdays from 10 a.m. to 5 p.m. Admission is free. It is intended that the Whipple Collection shall form the nucleus of a museum of the history of science in the University.

Prof. J. Hadamard will be unable to give the lecture announced for the annual general meeting of the London Mathematical Society on November 16. Prof. S. Mandelbrojt will give a lecture "On the Regularization of Sequences". It is hoped that Prof. Hadamard may be able to lecture at a later meeting. 